\title{
Ionization potentials and charge localization in small charged group 12 clusters.
}

\author{
R.-J. Tarento ${ }^{1}$ \\ 1 Laboratoire de Physique des Solides, \\ CNRS UMR 8502, Univ. Paris-Sud, \\ Université de Paris-Saclay F-91405 Orsay Cedex, France.
}

\begin{abstract}
For small size, the cluster $\mathrm{X}_{n}$ with $\mathrm{X}=\mathrm{Hg}$, Cd or Zn displays a van der Waals bond. A model Hamiltonian has been proposed for the singly (doubly) ionized van der Waals clusters $\mathrm{X}_{n}^{+}\left(\mathrm{X}_{n}^{++}\right)$. The first and second ionization potentials of $\mathrm{X}_{n}$ have been calculated. A good agreement is obtained with the available experiment values of the first ionization potential of mercury and cadmium. The stability and the metastability of $\mathrm{X}_{n}^{++}$are discussed. The energy curves versus the bond length for $\mathrm{Hg}_{2}^{++}, \mathrm{Cd}_{2}^{++}$and $\mathrm{Zn}_{2}^{++}$have been determined.
\end{abstract}

The hole(s) in charged clusters $\mathrm{X}_{n}^{+}$and $\mathrm{X}_{n}^{++}$for $2 \leq \mathrm{n} \leq 7$ is (are) mainly delocalized, except for $\mathrm{Hg}_{n}^{+}$ with $\mathrm{n} \geq 4$ where the hole is localized on 2 or 3 sites.

PACS numbers: 


\section{INTRODUCTION.}

The clusters built up with the 12 group elements ( $\mathrm{Hg}, \mathrm{Cd}$ and $\mathrm{Zn}$ ) have drawn attention to the nature of the chemical bonding. As the cluster size is increasing, a transition from van der Waals interaction to covalent and finally metallic behavior has been predicted and studied experimentally for mercury [1-18] and for cadmium [12, 19, 20]. Numerous amount of theoretical works [21-30] have been devoted to reveal the phase transitions in mercury clusters.

In the pioneer work by Brechignac et al [2, 4], the transition from van der Waals to covalent mercury clusters was observed at around $n=13-20$ through the measurements of inner shell excitation spectrum. The evolution of surface plasmon absorption has been observed with respect to the cluster size $[5,6]$. Nevertheless the measurement of the ionization potential by either photoionization $[11,12]$ or electron-impact ionization mass spectroscopy [3, 7] was the main technique to assess the transition of the chemical bond in neutral mercury clusters.

The fragmentation of multiply charged clusters provides some alternative knowledge on the mercury transition and the highly charged cluster stability, see the experiments by the Katakuse group [31] and the associated analysis in [32].

Some theoretical works have been devoted to compare the mercury, cadmium and zinc clusters $[33,35]$. Nevertheless the comparison of the calculated ionization potential values with experiments are not fully satisfying.

A model for small divalent singly ionized positive clusters of mercury has been proposed by Joyes and al. [25] to take into account the van der Waals character of the chemical binding. The Hamiltonian has been derived by fitting analytical expressions of the first ionization potential to experimental values. In the present article, we go further by analyzing the values of the different terms of the Hamiltonian obtained in Joyes et al paper [25] and we show that their values are in agreement with the basic physics knowledge.

Small clusters of group 12 elements like Zn and Cd have been less studied than mercury clusters but they are also expected to display some van der Waals characters in their chemical bonding. We transfer straightforwardly our knowledge on the parameter determination of the $\mathrm{Hg}_{n}^{+}$Hamiltonian to define the $\mathrm{Cd}_{n}^{+}$and $\mathrm{Zn}_{n}^{+}$Hamiltonian and compare the theoretical predictions of the ionization potential to available experiments for cadmium clusters.

As in van der Waals ionized clusters $\mathrm{Xe}_{n}^{+}$, the positive hole is localized [36, 37]. The hole 
localization is discussed in $\mathrm{Hg}_{n}^{+}, \mathrm{Cd}_{n}^{+}$and $\mathrm{Zn}_{n}^{+}$.

The second part deals with the doubly ionized clusters of mercury, cadmium and zinc. The Hamiltonian has to be modified mainly to take into account the possibility that the two charges are on one cluster atom. The second ionization potential is derived. The stability and metastability of $\mathrm{Hg}_{n}^{++}, \mathrm{Cd}_{n}^{++}$and $\mathrm{Zn}_{n}^{++}$is addressed. The dication of $\mathrm{X}_{2}^{++}$is discussed showing the metastability of $\mathrm{X}_{2}^{++}$.

\section{SMALL SINGLE IONIZED MERCURY CLUSTER $\mathbf{H G}_{n}^{+}, \mathrm{CD}_{n}^{+}$AND $\mathbf{Z N}_{n}^{+}, \mathbf{N} \leq 7$.}

The structure of the neutral aggregates $\mathrm{Hg}_{n}, \mathrm{Cd}_{n}$ and $\mathrm{Zn}_{n}$ with a small size $\mathrm{n}$ is van der Waals-like.

For instance, in the case of mercury, the s-band is completely separated from the p-band for $\mathrm{n}<10$. The energy difference between $6 \mathrm{~s}$ and $6 \mathrm{p}$ levels is large $(6.1 \mathrm{eV})$. Therefore it is justified to describe ionized aggregates by only considering the external 6 s levels for a cluster size $n<10$. Therefore in the neutral groundstate, each atom essentially keeps a $6 \mathrm{~s}^{2}$ configuration. This means that the cluster is essentially held by dispersion forces. One may think that as in ionized van der Waals aggregates $\left(\mathrm{Xe}_{n}^{+}[36,37]\right)$, the positive hole is localized on one (or on a few) central site.

The main features of the proposed model for $\mathrm{X}_{n}^{+}$aggregates with $\mathrm{X}=\mathrm{Hg}, \mathrm{Cd}$ or $\mathrm{Zn}$ and $\mathrm{n}<8$ are the following. The wave function is an expansion on a basis set of $\mathrm{n}$ determinants $\Phi_{i}$. Each $\Phi_{i}$ describes $(2 \mathrm{n}-1)$ electrons either $6 \mathrm{~s}$ for $\mathrm{Hg}$ or $5 \mathrm{~s}$ for $\mathrm{Cd}$ or $4 \mathrm{~s}$ for Zn which are distributed on $n$ atoms, we choose $n$ electrons up and n-1 electrons down. For the mercury case $\mathrm{n}=3$ (Fig.1), the 3 determinants are respectively $\operatorname{Det}\left(\phi_{6 s, \uparrow}(1) \phi_{6 s, \downarrow}(1) \phi_{6 s, \uparrow}(2) \phi_{6 s, \downarrow}(2) \phi_{6 s, \uparrow}(3)\right)$, $\operatorname{Det}\left(\phi_{6 s, \uparrow}(1) \phi_{6 s, \downarrow}(1) \phi_{6 s, \uparrow}(2) \phi_{6 s, \uparrow}(3) \phi_{6 s, \downarrow}(3)\right)$ and $\operatorname{Det}\left(\phi_{6 s, \uparrow}(1) \phi_{6 s, \uparrow}(2) \phi_{6 s, \downarrow}(2) \phi_{6 s, \uparrow}(3) \phi_{6 s, \downarrow}(3)\right)$ where $\phi_{6 s, \uparrow(\downarrow)}(\mathrm{i})$ is the 6 s atomic orbital centered on mercury atom i with spin $\uparrow(\downarrow)$.

The matrix elements of the nxn model Hamiltonian for $\mathrm{X}_{n}^{+}$are defined by

$$
<\Phi_{i}|H| \Phi_{i}>=(2 n-1) E_{V}+\sum_{j>j^{\prime}} E_{R}^{j, j^{\prime}}+\sum_{j>j^{\prime}} E_{\text {pol }}^{j, j^{\prime}}+\sum_{\substack{\text { doubly occupied } \\ \text { site } j}} U
$$

For $i \neq i^{\prime}\left\langle\Phi_{i}|H| \Phi_{i^{\prime}}\right\rangle=\beta$ if $\mid \Phi_{i}>$ and $\mid \Phi_{i^{\prime}}>$ differ by only one electron hopping

$$
\text { if not }<\Phi_{i}|H| \Phi_{i^{\prime}}>=0
$$

$\mathrm{j}$ and $\mathrm{j}$ ' labels sites. $E_{V}$ is the atomic level energy. $E_{R}^{j, j^{\prime}}$ is the repulsive energy between neutral nearest sites j and j'. $E_{\text {pol }}^{j, j^{\prime}}$ is the polarisation interaction between a positive site and a neutral site. $U$ is the on-site Comlomb integral. 
Let us discuss the determination of the Hamiltinian parameters. Firstly, $\mathrm{E}_{V}$ and $\mathrm{U}$ are atomic energies and are given respectively by

$$
\begin{gathered}
E_{V}=<6 s|H| 6 s> \\
U=\iint \psi_{6 s}(1) \psi_{6 s}^{\star}(1) \frac{e^{2}}{r_{12}} \psi_{6 s}(2) \psi_{6 s}^{\star}(2) d r_{1} d r_{2}
\end{gathered}
$$

To be coherent with the atomic data of either mercury or zinc or cadmium, $\mathrm{E}_{V}$ and $\mathrm{U}$ are determined from the first (second) atomic ionization potential $\left(\mathrm{I}_{p} \mathrm{I}_{p}^{I I}\right)$ of either mercury or zinc or cadmium. They are linked by the following relations

$$
\begin{gathered}
E_{V}=E\left(X^{+}\right)-E\left(X^{++}\right)=-I_{p}^{I I} \\
U=E(X)-E\left(X^{+}\right)-E_{V}=I_{p}^{I I}-I_{p}
\end{gathered}
$$

where $\mathrm{E}(\mathrm{X}), \mathrm{E}\left(\mathrm{X}^{+}\right)$and $\mathrm{E}\left(\mathrm{X}^{++}\right)$are respectively the energy of the neutral, singly ionized and doubly ionized $\mathrm{X}$ atom $(\mathrm{X}=\mathrm{Hg}, \mathrm{Cd}$ or $\mathrm{Zn})$. The values of $\mathrm{E}_{V}$ and $\mathrm{U}$ are reported in Table.I.

The hopping term $\beta(\mathrm{d})$ is the transfer energy between two adjacent sites and is dependent on their distance d. Two generic kinds of cluster geometry are investigated, either regular clusters having equal distances between nearest neighbors which are short and equal to $\mathrm{d}_{1}$ or irregular clusters with two possible distances between nearest neighbors $d_{1}$ and $d_{2}$ with $d_{2}>$ $\mathrm{d}_{1}$. From a study of $\mathrm{Xe}_{n}^{+}$by Durand et al [37], the ratio $\frac{d_{2}}{d_{1}}$ could be estimated close to 1.4. As $\beta(\mathrm{d})$ is proportional to $d^{-2}[38], \beta\left(\mathrm{d}_{2}\right)$ is close to $\frac{\beta\left(d_{1}\right)}{2}$. Thus we will use $\beta\left(\mathrm{d}_{2}\right)=\frac{\beta\left(d_{1}\right)}{2}$ in our calculation. The good agreements of our results with experiments on the ionization potential of mercury and cadmium clusters will give confidence on our $\beta\left(\mathrm{d}_{2}\right)$ choice.

$\mathrm{E}_{R}^{i, j}$ is the repulsion energy between two neutral atoms $\mathrm{i}$ and $\mathrm{j}$ and is assumed equal to a parameter $E_{R}$ if the distance $\mathrm{d}$ between sites $\mathrm{i}$ and $\mathrm{j}$ is equal to $\mathrm{d}_{1}$. We assume that $\mathrm{E}_{R}^{i, j}$ is negligible for $\mathrm{d}=\mathrm{d}_{2} . \mathrm{E}_{\text {pol }}^{i, j}$ is the attractive polarization energy between an ionized site $\mathrm{i}$ and a neutral site $\mathrm{j}$ and is assumed equal to a parameter $\mathrm{E}_{p o l}$ if $\mathrm{d}=\mathrm{d}_{1}$. We also assume that $\mathrm{E}_{\text {pol }}^{i, j}$ is negligible for $\mathrm{d}=\mathrm{d}_{2}$. Our assumptions on the variations with $\mathrm{d}$ of $\beta, \mathrm{E}_{R}^{i, j}$ and $\mathrm{E}_{\text {pol }}^{i, j}$ are justified by the fact that $\beta$ decreases more slowly than the other two parameters when d increases.

In a first step, let us determine the Hamiltonian parameters of the mercury clusters. $\beta\left(\mathrm{d}_{1}\right), \mathrm{E}_{R}$ and $\mathrm{E}_{\text {pol }}$ of $\mathrm{Hg}_{n}^{+}$are derived by fitting analytical expressions of the first ionization energy $\mathrm{I}_{p}\left(\mathrm{Hg}_{n}\right)$ for $\mathrm{n}=2-4$ to the experimental results. In a second step, the fitting parameter 
values will be analyzed. The ionization energy of mercury cluster $\mathrm{I}_{P}\left(\mathrm{Hg}_{n}\right)$ is equal to $\mathrm{E}\left(\mathrm{Hg}_{n}^{+}\right)$$\mathrm{E}\left(\mathrm{Hg}_{n}\right)$. Analytical expressions of the singly ionized cluster energies $\mathrm{E}\left(\mathrm{Hg}_{n}^{+}\right)$are expressed from the Hamiltonian for cluster size $\mathrm{n}=2,3$ and 4 and are given in Table.II with geometries involving either only the distance $\mathrm{d}_{1}$ or the distances $\mathrm{d}_{1}$ and $\mathrm{d}_{2}$. For each $\mathrm{n}$ value, we are looking for the lowest energy cluster configuration among shapes corresponding to regular and irregular polyhedra, chain and ring.

The model disregards the p-orbitals, for instance the 6p-orbitals for mercury. So it will not be easy to treat the neutral species. But the neutral cluster energy $\mathrm{E}\left(\mathrm{Hg}_{n}\right)$ can be obtained by considering compact shapes. $\mathrm{E}\left(\mathrm{Hg}_{n}\right)$ is equal to $2 \mathrm{n} \mathrm{E}_{V}+\mathrm{n} \mathrm{U}+\mathrm{E}_{v d W}(\mathrm{n})$. The van der Waals binding energy $\mathrm{E}_{v d W}(\mathrm{n})$ is derived from the dimer $\mathrm{E}_{v d W}(2)$ and takes into account the number of nearest neighbor interaction. $\mathrm{E}_{v d W}(2)$ is estimated to $0.07 \mathrm{eV}$ [39] for mercury to get energy values similar to the Bennemann et al results [22, 24] for small cluster size.

By fitting the analytical expressions of $\mathrm{I}_{p}\left(\mathrm{Hg}_{n}\right)$ to the experimental results [3] and by keeping the most stable shapes of $\mathrm{Hg}_{n}^{+}$for $\mathrm{n}=2-4, \beta\left(\mathrm{d}_{1}\right), \mathrm{E}_{R}$ and $\mathrm{E}_{\text {pol }}$ are determined and reported in Table.I.

Let us go further and discuss the values of the derived parameters $\beta\left(\mathrm{d}_{1}\right), \mathrm{E}_{R}$ and $\mathrm{E}_{\text {pol }}$ of the $\mathrm{Hg}_{n}^{+}$model.

The $\beta\left(\mathrm{d}_{1}\right)$ value derived by fitting is close to the hopping term value calculated with the Harrison formula [38]

$$
\beta_{\text {Har }}(R)=-1.40 \frac{h^{2}}{m R^{2}}
$$

with the interatomic distance $\mathrm{R}$, the Planck constant $\mathrm{h}$ and the electron mass $\mathrm{m}$. Taking $\mathrm{R}=\mathrm{d}_{1}=3.63 \AA$ which is an experimental nearest neighbor distance value [34] close to a theoretical one [35], Eq.4 gives a value of $0.81 \mathrm{eV}$ instead of the fitting value $\beta\left(\mathrm{d}_{1}\right)$ is $0.8 \mathrm{eV}$.

The fitting value of $\mathrm{E}_{R}$ is close to the calculated value derived from a classical Born-Meyer potential

$$
E_{R}^{B-M}(R)=A \exp (-b R)
$$

with $\mathrm{A}=60678 \mathrm{eV}$ and $\mathrm{b}=3.50084 \AA^{-1}[40]$. Eq.5 gives a value of $0.19 \mathrm{eV}$ instead of a fitting $\mathrm{E}_{R}$ value of $0.43 \mathrm{eV}$.

Likewise, the fitting $\mathrm{E}_{p o l}$ value is close to the value given by the interaction energy $\left(\mathrm{E}^{C h-I n t-D i p}\right)$ between a charge $(\mathrm{z}$ e) and the induced dipole 


$$
E^{C h-I n t-D i p}=-\left(\frac{z e}{4 \pi \epsilon_{o}}\right)^{2} \frac{\alpha}{2 R^{4}}
$$

where $\alpha$ is the mercury atomic polarisability. Using a value for $\alpha$ obtained from the Nagle paper [41], Eq.6 gives an energy $\mathrm{E}^{C h-I n t-D i p}$ of $0.22 \mathrm{eV}$ close to the fitting $\mathrm{E}_{\text {pol }}$ value of $0.27 \mathrm{eV}$.

In summary, the values of $\beta\left(\mathrm{d}_{1}\right), \mathrm{E}_{R}$ and $\mathrm{E}_{\text {pol }}$ of the mercury cluster Hamiltonian can be interpreted with the basic physics knowledge.

Cadmium and zinc clusters have been less studied although they deserve attention for the van der Waals interaction displayed by the smallest clusters. In our knowledge, only one group reports on the cadmium cluster ionization potential $\mathrm{I}_{p}\left(\mathrm{Cd}_{n}\right)[12,19,20]$ and only one study of the ionization potential of $\mathrm{Zn}_{2}$ [42] is available. Our choice has been to transfer straightforwardly our knowledge acquired on mercury cluster to $\mathrm{Zn}$ and $\mathrm{Cd}$ clusters. It means that $\mathrm{E}_{V}$ and $\mathrm{U}$ are determined from the atomic data of $\mathrm{Zn}$ and $\mathrm{Cd}$ using Eqs.3. $\beta\left(\mathrm{d}_{1}\right), \mathrm{E}_{R}$ and $\mathrm{E}_{p o l}$ are fixed by Eqs.4-6 using the calculated distances $\mathrm{d}_{Z n}=3.96 \AA[35]$ and $\mathrm{d}_{C d}=3.96 \AA$ [35], the atomic polarisabilities from [41] and the Born-Meyer potentials from [40]. The values of the Hamiltonian parameters for cadmium and zinc are reported in Table.I. U, $\mathrm{E}_{V}$ and $\beta\left(\mathrm{d}_{1}\right)$ are close for $\mathrm{Hg}, \mathrm{Zn}$ and $\mathrm{Cd}$ while $\mathrm{E}_{R}$ of $\mathrm{Zn}$ and $\mathrm{Cd}$ is a magnitude smaller than the $\mathrm{Hg}$ value. $\mathrm{E}_{\text {pol }}$ has a similar value for cadmium and mercury whereas the zinc value is 3 times larger. $\mathrm{E}_{R}$ is an important parameter to balance the attractive energy due to $\mathrm{E}_{\text {pol }}$ and therefore to avoid the overlap of the electronic cloud. Therefore the transition from Van der Waals to metallic in cadmium and zinc is expected to occur for smaller cluster size than for Hg clusters.

\section{THE MERCURY, ZINC AND CADMIUM SINGLY IONIZED CLUSTERS RE- SULTS.}

For each size $\mathrm{n}$, we are looking for the geometry of the lowest energy $\mathrm{X}_{n}^{+}$associated with the Hamiltonian $\mathrm{H}$ defined by the parameters of Table.I.

In the mercury case, the geometries of the most stable $\mathrm{Hg}_{n}^{+}$are reported in Fig.2 for $\mathrm{n}=2-7$ and are quite similar to the Garcia results [24]. For $\mathrm{n} \leq 3$, all the nearest neighbor distances are equal while for $4 \leq \mathrm{n} \leq 7, \mathrm{Hg}_{n}^{+}$exhibit two nearest neighbor distance values.

The clusters $\mathrm{Cd}_{n}^{+}$and $\mathrm{Zn}_{n}^{+}$with $2 \leq \mathrm{n} \leq 7$ display the same geometries than the clusters $\mathrm{Hg}_{n}^{+}$ but all the nearest neighbor distances are equal. The $\mathrm{Cd}_{n}^{+}$and $\mathrm{Zn}_{n}^{+}$shapes are more compact. 
It is related to the small value of $\mathrm{E}_{R}$ compared to $\mathrm{E}_{p o l}$.

The (non)-localization of the hole is an interesting question which has already been addressed in the van der Waals $\mathrm{Xe}_{n}^{+}$clusters and has been discussed for $\mathrm{Hg}_{n}^{+}[24,25]$. As seen below, the localization has a link with the geometry of the cluster.

For $\mathrm{n} \leq 3$, the singly ionized mercury clusters have regular shapes and the positive charge is shared between all the sites which are almost equivalent. The hole is delocalized on the whole cluster. But for $\mathrm{n} \geq 4$, the mercury cluster shapes are irregular and the hole is meanly localized on a limited number of mercury sites (2 or 3$)$ which are painted in red in Fig.2. In Table.III, the weight $\mathrm{W}$ of the localized configurations, i.e. the probability of localization of the hole on the red mercury sites are reported. The weight is decreasing with the size. Garcia et al [23] has found that the positive charge is meanly distributed within a trimer which is located at the center of the cluster.

The clusters $\mathrm{Cd}_{n}^{+}$and $\mathrm{Zn}_{n}^{+}$with $2 \leq \mathrm{n} \leq 7$ have a regular and compact shape and the hole is always delocalized on the whole cluster (Table.III).

Both in Fig.3 and Table.IV, the calculated first ionization potentials of $\mathrm{Hg}, \mathrm{Zn}$ and $\mathrm{Cd}$ clusters for size $\mathrm{n}=2-7$ are reported. The present model give similar trends of $\mathrm{I}_{p}$ versus the cluster size. The comparisons of the size depencence of $\mathrm{I}_{p}\left(\mathrm{Cd}_{n}\right)$ and $\mathrm{I}_{p}\left(\mathrm{Hg}_{n}\right)$ with the experiments quoted respectively in the articles [19] and [3] are quite good and confirm our approach, in particular our choice of $\beta(\mathrm{d} 2)$. The present $\mathrm{I}_{p}\left(\mathrm{Hg}_{n}\right)$ dependence versus the size is quite similar to the Garcia results [24]. In the zinc case, the calculated $\mathrm{I}_{p}\left(\mathrm{Zn}_{2}\right)$ value of $8.61 \mathrm{eV}$ is close to the experimental value of $9 \mathrm{eV} \pm 0.2 \mathrm{eV}[42]$.

In conclusion, the present model developed for the clusters $\mathrm{Hg}_{n}^{+}, \mathrm{Cd}_{n}^{+}$and $\mathrm{Zn}_{n}^{+}$agrees quite well with experiments for small cluster size and supports the van der Waals interaction in small mercury and cadmium clusters.

\section{THE DOUBLY IONIZED CLUSTERS $\mathbf{H G}_{n}^{++}, \mathrm{CD}_{n}^{++}$AND $\mathbf{Z N}_{n}^{++}$.}

The model developed for the singly ionized cluster $\mathrm{X}_{n}^{+}$can be extended to the doubly ionized cluster $\mathrm{X}_{n}^{++}(\mathrm{X}=\mathrm{Hg}, \mathrm{Cd}$ or $\mathrm{Zn})$.

In the doubly ionized cluster $\mathrm{X}_{n}^{++}$case, the wavefunction is built up with either Slater determinants in which the two holes are on one site and the other n-2 sites have two electrons or with Slater determinants in which two holes are on two different sites and the other n-2 
sites have two electrons. For instance, the 9 determinant states of the case $n=3$ are displayed in Fig.4. The size of the Slater determinant basis to describe $\mathrm{X}_{n}^{++}$increases strongly with the cluster size.

The presence of two holes in the cluster requires to include in Eq.1 an extra coulombic term when the determinant state has two holes located on two different sites. Moreover the polarization energy between a neutral atom and a site with two holes is 4 times the term $\mathrm{E}_{\text {pol }}$ see Eq.5.

In a first step, we keep the values of the parameters of the Hamiltonian given in Table.I. It means that the nearest neighbor ditances are conserved. In particular, this assumption allows us to determine the vertical second ionization potential. With this assumption, for $\mathrm{n} \leq 4$, the lowest energy cluster shapes of $\mathrm{X}_{n}^{++}$are similar to the shapes of $\mathrm{X}_{n}^{+}$. All the distances between nearest atoms are equal and the holes are delocalized. The effect is due to a larger polarization energy contribution. Notice that the Slater determinants with two holes on the same site do not contribute significantly to the cluster state. The vertical second ionization potential of $\mathrm{X}_{n}^{++}$are given in Table.V. We do not take any vibrational corrections into account. The zero-point energies $\mathrm{E}_{Z-E}\left(\mathrm{X}_{2}^{++}\right)$for $\mathrm{X}_{2}^{++}$could be estimated using the force constants associated to the minima of the potential curves plotted in Fig.5 thus $\mathrm{E}_{Z-E}\left(\mathrm{Hg}_{2}^{++}\right)=0.008 \mathrm{eV}, \mathrm{E}_{Z-E}\left(\mathrm{Cd}_{2}^{++}\right)=0.016 \mathrm{eV}$ and $\mathrm{E}_{Z-E}\left(\mathrm{Zn}_{2}^{++}\right)=0.024 \mathrm{eV}$. The values of $\mathrm{E}_{Z-E}\left(\mathrm{X}_{2}^{++}\right)$are quite smaller than the atomization energies of $\mathrm{X}_{2}^{++}$given in Table.VI what suggests that the vibrational corrections are not so important.

The stability of small highly charged van der Waals clusters is still a question. Let us get some informations on the stability of $\mathrm{X}_{n}^{++}$discussed just before by studying the atomization energy $\left(\mathrm{D}_{E}\right)$ of $\mathrm{X}_{n}^{++}$which is defined by the comparison between the energy of $\mathrm{X}_{n}^{++}$and the sum of the energies of all the different species which build the cluster i.e:

$$
D_{E}=E\left(X_{n}^{++}\right)-(n-2) E(X)-2 E\left(X^{+}\right)
$$

Beware of our choice of $\mathrm{D}_{E}$ which is just the opposite of what is usually used, for instance, to define the binding energy. In Table.VI, the values of $\mathrm{D}_{E}$ are reported. In the present calculation, the atomization energy begins to be negative only for $\mathrm{X}_{4}^{++}$both for $\mathrm{X}=\mathrm{Hg}$, $\mathrm{Zn}$ and $\mathrm{Cd}$ i.e that $\mathrm{X}_{4}^{++}$could be stable for $\mathrm{n} \geq 4$. To go beyond, let us investigate the different channels of fragmentation of $\mathrm{X}_{4}^{++}$. The channels and their energy (Q-value) are reported in Table.VII. A negative $\mathrm{Q}$-value means that $\mathrm{X}_{4}^{++}$has a trend to fragmentation. 
The energies are more negative for $\mathrm{Cd}_{4}^{++}$and $\mathrm{Zn}_{4}^{++}$suggesting that they are relatively less stable than $\mathrm{Hg}_{4}^{++}$. For $\mathrm{Hg}_{4}^{++}$, the symmetric dissociation $\left(\mathrm{Hg}_{4}^{++} \rightarrow \mathrm{Hg}_{2}^{+}+\mathrm{Hg}_{2}^{+}\right)$seems to be the main channel compared to the asymmetric one $\left(\mathrm{Hg}_{4}^{++} \rightarrow \mathrm{Hg}_{3}^{+}+\mathrm{Hg}^{+}\right)$what is in agreement with a previous study [32]. For $\mathrm{Cd}_{4}^{++}$and $\mathrm{Zn}_{4}^{++}$, The $\mathrm{Q}$-value has a close value for the symmetric and asymmetric channels. To go beyond, need to study the fragmentation barrier and the topology of the energy surface of the Hamiltonian. But for the symmetric fragmentation channel, the Q-value seems strongly decreasing with the size in fact the Qvalue is respectively equal to $-0.70 \mathrm{eV},-1.04 \mathrm{eV}$ and $-1.14 \mathrm{eV}$ for $\mathrm{Hg}_{4}^{++}, \mathrm{Cd}_{4}^{++}$and $\mathrm{Zn}_{4}^{++}$and the Q-value has respectively a value of $-3.19 \mathrm{eV},-3.20 \mathrm{eV}$ and $-3.28 \mathrm{eV}$ for $\mathrm{Hg}_{2}^{++}, \mathrm{Cd}_{2}^{++}$and $\mathrm{Zn}_{2}^{++}$.

The present results suggest to study the metastability of $\mathrm{Hg}_{n}^{++}$with $\mathrm{n}$ close to 4, in relation with the experimental reports of mestable $\mathrm{Hg}_{n}^{++}$for $\mathrm{n}=5$ [10] and 7 [15]. In their study of $\mathrm{Hg}_{2}^{++}$, Neisler [43] and Durand et al [44] find that $\mathrm{Hg}_{2}^{++}$display a metastability. Is it possible to study the metastability of $\mathrm{X}_{2}^{++}$with our approach? The answer is yes by assuming a distance dependence of the Hamiltonian and to compare our results on $\mathrm{Hg}_{2}^{++}$ with previous works. Our choice of the distance dependence of the Hamiltonian is linked with the dependence given by Eqs.4-6.

The energy of $\mathrm{X}_{2}^{++}$versus the distance are reported in Fig.5. Also shown is the electrostatic repulsive curve for two single charges $\left(\mathrm{e}^{2} / \mathrm{r}\right)$. For $\mathrm{Hg}_{2}^{++}$, the energy dependence derived with the present modified Hamiltonian is similar to the previous studies $[43,44] . \mathrm{Hg}_{2}^{++}$is metastable for $\mathrm{r}$ close to $2.4 \AA$ which is a shorter length compared to the bond length in neutral and singly ionized mercury clusters. A $\mathrm{D}_{E}$ value for metastable $\mathrm{Hg}_{2}^{++}$is reported by Neisler and al [43] and is worth $1.56 \mathrm{eV}(2.51 \mathrm{eV})$ in a (non)relativistic CI calculations associated with a bond distance of $2.53(2.81) \AA$. The present calculations give a bond distance of $2.45 \AA$, a dissociation energy of $2.21 \mathrm{eV}$ and a dissociation barrier of $1.03 \mathrm{eV}$ for $\mathrm{Hg}_{2}^{++}$. For $\mathrm{Cd}_{2}^{++}\left(\mathrm{Zn}_{2}^{++}\right)$, the bond distance is equal to $2.40(2.46) \AA$, the dissociation energy is worth $1.89(2.36) \mathrm{eV}$ and the dissociation barrier is worth $1.38(0.92) \mathrm{eV}$. For the dissociation distance range, the Slater determinants with two holes on the same site contribute to the cluster state. Note that for large $\mathrm{r}$, the energy decreases like $\frac{1}{r}$.

Finally let us report that metastable $\mathrm{Cd}_{2}^{++}$have been observed in the gas phase [45]. A diatomic dication formation of $\mathrm{Cd}_{2}^{++}$due to the resonant collisional electron-transfer process was used to explain the presence of metastable $\mathrm{Cd}_{2}^{++}$. Our calculations confirm the metasta- 
bility of $\mathrm{Cd}_{2}^{++}$and also of $\mathrm{Zn}_{2}^{++}$in agreement with the fact that the homonuclear diatomic dication $\mathrm{X}_{2}^{++}$cannot be thermodynamically stable [46].

\section{CONCLUSION}

For $\mathrm{X}_{n}^{+}$and $\mathrm{X}_{n}^{++}$with $\mathrm{n} \leq 7(\mathrm{X}=\mathrm{Hg}, \mathrm{Cd}$ and $\mathrm{Zn})$, a model Hamiltonian has been developed for the singly and doubly ionized van der Waals cluster of mercury, cadmium and zinc. The first and second ionization potential has been derived and a good agreement with experiments is obtained for mercury and cadmium first ionization potential.

For $\mathrm{n} \leq 7$, the stable shapes of $\mathrm{X}_{n}^{+}$and $\mathrm{X}_{n}^{++}$are generally compact and has only one bond length between nearest atoms. The hole(s) is (are) delocalized. It is linked to the larger contribution of the polarization energy than the repulsion energy. However, for $\mathrm{Hg}_{n}^{+}$with $\mathrm{n} \geq 4$, the shape displayed two bond lengths between nearest atoms and the hole is localized on 2 or 3 sites.

The stability of $\mathrm{X}_{n}^{++}$is still an open question. The present Hamiltonian give results on the metastability of $\mathrm{Hg}_{2}^{++}, \mathrm{Cd}_{2}^{++}$and $\mathrm{Zn}_{2}^{++}$similar to the ab initio calculations [43, 44]. It will be an interesting perpective to investigate the stability and metastabilty of larger clusters 
[1] E. Pahl and P. Schwerdtfeger, in Handbook of Nanophysics: Clusters and Fullerenes, edited by K. Satler (CRC Press, Boca Raton, 2011), Vol. 2, Part I.

[2] C. Bréchignac, M. Broyer,Ph. Cahuzac,G. Delacretaz, P. Labastie and L. Wöste, Chem.Phys.Lett 120, 559 (1985).

[3] B. Cabaud, A. Hoareau and P Melinon, J.Phys.D 13, 1831 (1980).

[4] C. Bréchignac, M. Broyer, Ph. Cahuzac, G. Delacretaz, P. Labastie, J.P. Wolf, and L. Wöste, Phys.Rev.Lett. 60, 275 (1988).

[5] K. Rademann, O. Dimopoulou-Rademann, M. Schlauf, U. Even, and F. Hensel, Phys.Rev.Lett. 69, 3208 (1992).

[6] H. Haberland, B. von Issendorff, J. Yufeng, and T. Kolar, Phys.Rev.Lett. 69, 3212 (1992)

[7] H. Haberland, H. Kornmeier, H. Langosch, M. Oschwald, and G. Tanner, J.Chem.Soc., Faraday Trans. 86, 2473 (1990).

[8] R. Busani, M. Folkers, and O. Cheshnovsky, Phys.Rev.Lett. 81, 3836 (1998)

[9] H. Ito, T. Sakurai, T. Matsuo, T. Ichihara, and I. Katakuse, Phys.Rev.B 48, 4741 (1993).

[10] J. Blanc, M. Broyer, Ph. Dugourd, P. Labastie, M. Sence, J.P. Wolf, and L.Wöste, J.Chem.Phys. 102, 680 (1995).

[11] K. Rademann, B. Kaiser, U. Even and F. Hensel, Phys.Rev.Lett. 59, 2319 (1987).

[12] K. Rademann, M. Ruppel and B. Kaiser, Ber.Bunsenges.Phys.Chem. 96, 1204 (1992).

[13] B. Kaiser and K. Rademann, Phys.Rev.Lett. 69, 3204 (1992).

[14] B. Lang, A. Vierheilig, E. Wiedenmann, H. Buchenau, and G. Gerber, Eur.Phys.J.D 40, 1 (1997).

[15] B. Bescòs, B. Lang, J. Weiner, V. Weiss, E. Wiedenmann, and G. Gerber, Eur.Phys.J.D 9, 399 (1999).

[16] J.R.R. Verlet, A.E. Bragg, A. Kammrath, O. Cheshnovsky, and D.M. Neumark, J.Chem.Phys. 121, 10015 (2004).

[17] A.E. Bragg, J.R.R. Verlet, A. Kammrath, O. Cheshnovsky, and D.M. Neumark, J.Chem.Phys. 122, $054314(2005)$.

[18] R.M. Young, G.B. Griffin, O.T Ehrler, A. Kammrath, A.E. Bragg, J.R.R. Verlet, O. Cheshnovsky, and D.M. Neumark, Phys. Scr. 80, 48102 (2009). 
[19] M. Ruppel and K. Rademann, Chem.Phys.Lett 197, 280 (1992).

[20] K. Rademann, J.Non-Cryst.Solids. 156-158, 794 (1993).

[21] G.M. Pastor and K.H. Bennemann, in Clusters of Atoms and Molecules, edited by H. Haberland, Vol.I (Spriger, Berlin, 1995) 7, pp 86-113.

[22] G.M. Pastor, P. Stampfli and K.H. Bennemann, Europhysics.Lett. 7, 419 (1988).

[23] M.E. Garcia, G.M. Pastor and K.H. Bennemann, Phys.Rev.Lett. 67, 1142 (1991).

[24] M.E. Garcia, G.M. Pastor and K.H. Bennemann, Phys.Rev.B. 48, 8388 (1993).

[25] P. Joyes and R.J. Tarento, J.Phys.France 50, 2673 (1989).

[26] A.A. Aligia, M.E. Garcia, and K.H. Bennemann, Europhys.Lett. 21, 177 (1993).

[27] H. Kitamura, J.Phys.: Condens.Matter 15, 6427 (2003).

[28] H. Kitamura, Chem.Phys.Lett. 425, 205 (2006).

[29] M. Dolg and H.-J. Flad, Mol.Phys. 91, 815 (1997).

[30] F. Calvo, E. Pahl, P. Schwerdtfeger and F. Spiegelman, J.Chem. Theory Comput. 8, 639 (2012).

[31] T. Satoh, H. Ito, T. Ichihara, H. Sakae and I. Katakuse, J.Mass.Spectrom.Jpn. 51, 393 (2003).

[32] M. Nakamura and R.J.Tarento , J.Chem.Phys. 148, 084312 (2018).

[33] H.-J. Flad, F. Schautz, Y. Wang, M. Dolg, and A. Savin, Eur.Phys.J.D 6, 243 (1999).

[34] R.D. van Zee, S.C. Blankespoor and T.S. Zwier, J.Chem.Phys 88, 4650 (1988).

[35] M. Yu and M. Dolg, Chem.Phys.Lett 273, 329 (1997).

[36] M. Amarouche, G. Durand and J.P Malrieu, J.Chem.Phys. 88, 1010 (1988).

[37] M. Amarouche, G. Durand and J.P Malrieu, Z.Phys.D, 8, 289 (1988).

[38] W.A. Harrison, Electronic structure and the properties of solids edited by W.H Freeman and Company San Francisco, (1980).

[39] The van der Waals binding energies of $\mathrm{Cd}$ and $\mathrm{Zn}$ is derived from the value of $\mathrm{Hg}$ using the $\mathrm{Cd}(\mathrm{Zn})$ atomic polarisability and the interatomic distance which are both reported in the article.

[40] A.A. Abrahamson, Phys.Rev 178, 76 (1969).

[41] J.K. Nagle, J.Am.Chem.Soc 112, 4741 (1990).

[42] S.W. Buckner, J.R Gord and B.S Freiser, J.Chem.Phys. 88, 3678 (1988).

[43] R.P. Neisler and K.S. Pitzer, J.Phys.Chem 911084 (1987).

[44] G. Durand, F. Spiegelmann and A. Bernier, J.Phys.B 801161 (1987). 
[45] K. Franzreb, R. Pies Diez and J.A. Alonso, J.Chem.Phys 130144312 (2009).

[46] M. Kolbuszewski and J.S. Wright, Can.J.Chem 711562 (1993).
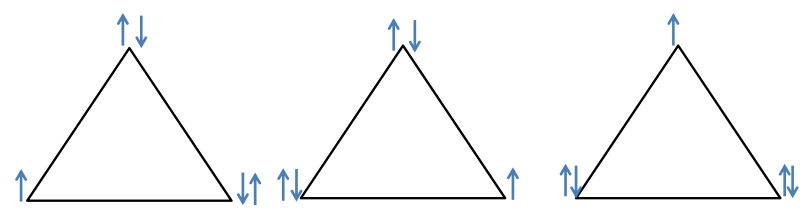

FIG. 1: The 3 Slater determinant functions for $\mathrm{X}_{3}^{+}$
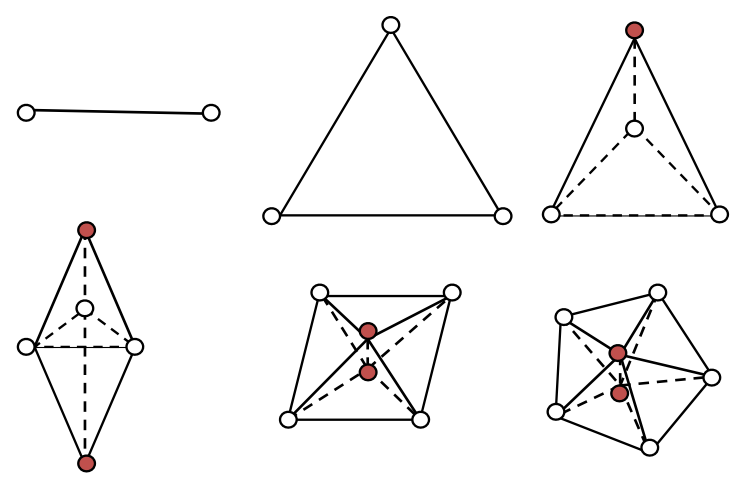

FIG. 2: The stablest shape for $\mathrm{Hg}_{n}^{+}$. The sites where the hole is more localized are the red solid circle. 


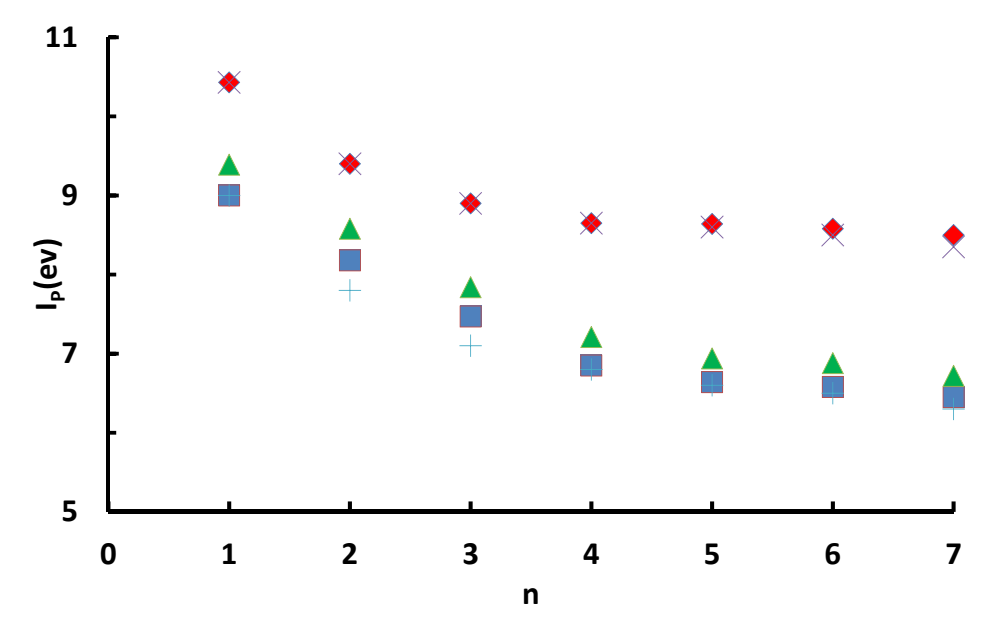

FIG. 3: First ionizattion potential $\mathrm{I}_{P}(\mathrm{eV})$ versus the cluster size of $\mathrm{Hg}_{n}(\bullet:$ present work, $\times$ : experiments $[2,3]), \mathrm{Cd}_{n}(\boldsymbol{\square}:$ present work, $+[19])$ and $\mathrm{Zn}_{n}(\Delta$ : present work)
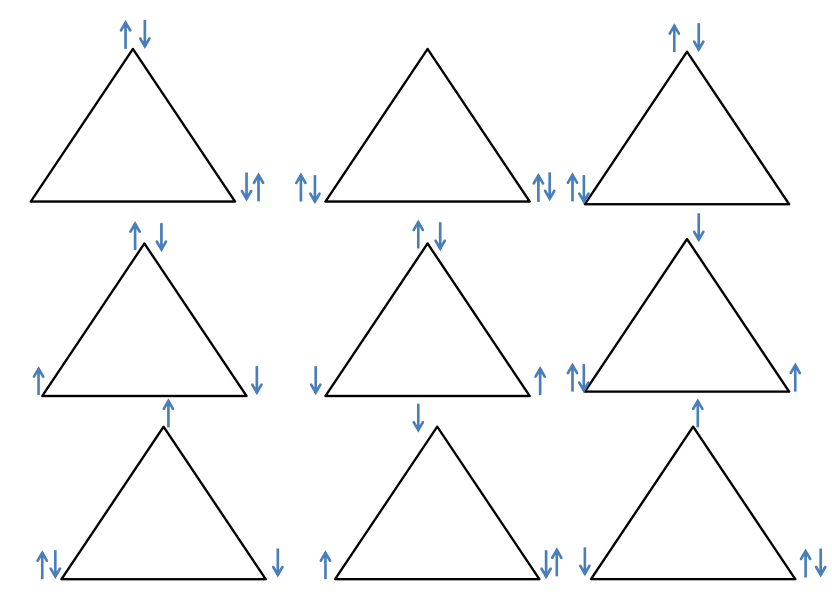

FIG. 4: The 9 Slater determinant functions for $\mathrm{X}_{3}^{++}$ 

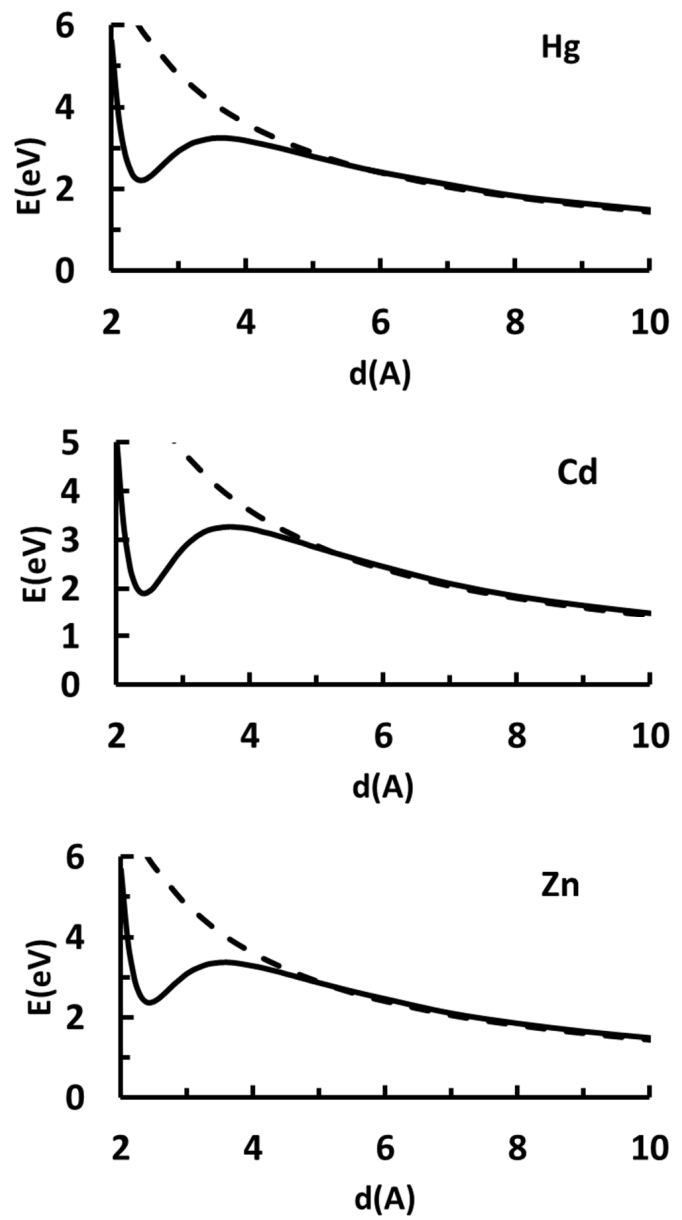

FIG. 5: The $\mathrm{Hg}_{2}^{++}, \mathrm{Cd}_{2}^{++}$and $\mathrm{Zn}_{2}^{++}$energy curves $\mathrm{E}(\mathrm{eV})$ versus the distance $\mathrm{d}(\ddot{A})$. The zero energy is for $2 \mathrm{X}^{+}$. The electrostatic repulsion of two single charges is shown dashed $\left(\mathrm{e}^{2} / \mathrm{r}\right)$.

TABLE I: Values of the parameters (in eV) for small $\mathrm{Hg}_{n}^{+}, \mathrm{Cd}_{n}^{+}$or $\mathrm{Zn}_{n}^{+}$.

\begin{tabular}{|c|c|c|c|}
\hline & $\mathrm{Hg}$ & $\mathrm{Cd}$ & $\mathrm{Zn}$ \\
\hline $\mathrm{E}_{V}$ & -18.6 & -16.9 & -17.96 \\
\hline $\mathrm{U}$ & 8.2 & 7.91 & 8.57 \\
\hline$\beta_{1}=\beta\left(\mathrm{d}_{1}\right)$ & -0.8 & -0.68 & -0.68 \\
\hline$\beta_{2}=\beta\left(\mathrm{d}_{2}\right)$ & -0.4 & -0.34 & -0.34 \\
\hline $\mathrm{E}_{R}$ & 0.43 & 0.025 & 0.011 \\
\hline $\mathrm{E}_{\text {pol }}$ & -0.27 & -0.21 & -0.23 \\
\hline
\end{tabular}


TABLE II: Energies of the localized and delocalized states versus the size.

\begin{tabular}{|c|c|c|c|}
\hline $\mathrm{n}$ & 2 & 3 & 4 \\
\hline $\mathrm{E}\left(\mathrm{Hg}_{n}^{+}\right)$delocalized & $3 \mathrm{E}_{V}+\mathrm{U}+\beta_{1}+\mathrm{E}_{p o l}$ & $5 \mathrm{E}_{V}+2 \mathrm{U}+\mathrm{E}_{R}+2 \beta_{1}+2 \mathrm{E}_{p o l}$ & $7 \mathrm{E}_{V}+3 \mathrm{U}+3 \mathrm{E}_{R}+3 \beta_{1}+3 \mathrm{E}_{p o l}$ \\
\hline & & $\left(\mathrm{E}_{1}+\mathrm{E}_{2}+\beta_{1}-\sqrt{\Delta}\right) / 2$ & $\left(\mathrm{E}_{1}+\mathrm{E}_{2}+2 \beta_{1}-\sqrt{\Delta}\right) / 2$ \\
$\mathrm{E}\left(\mathrm{Hg}_{n}^{+}\right)$localized & $3 \mathrm{E}_{V}+\mathrm{U}+\beta_{1}$ & where $\Delta=\left(\mathrm{E}_{1}-\mathrm{E}_{2}-\beta_{1}\right)^{2} \ldots$. & where $\Delta=$ \\
& &..$+4 \beta_{2}\left(\beta_{1}+\beta_{2}\right)$ & $\left(\mathrm{E}_{1}-\mathrm{E}_{2}-2 \beta_{1}\right)^{2}+12 \beta_{2}^{2}$ \\
& & $\mathrm{E}_{1}=5 \mathrm{E}_{V}+2 \mathrm{U}+\mathrm{E}_{R}$ & $\mathrm{E}_{1}=7 \mathrm{E}_{V}+3 \mathrm{U}+3 \mathrm{E}_{R}$ \\
& & $\mathrm{E}_{2}=5 \mathrm{E}_{V}+2 \mathrm{U}+\mathrm{E}_{p o l}$ & $\mathrm{E}_{2}=7 \mathrm{E}_{V}+3 \mathrm{U}+2 \mathrm{E}_{R}+\mathrm{E}_{p o l}$ \\
& &
\end{tabular}

TABLE III: Size dependence of the weight $\mathrm{W}$ of the hole localization for $\mathrm{Hg}_{n}^{+}, \mathrm{Cd}_{n}^{+}$or $\mathrm{Zn}_{n}^{+}$(delocalized means that the hole is delocalized).

\begin{tabular}{|c|c|c|c|}
\hline $\mathrm{W}$ & $\mathrm{Hg}$ & $\mathrm{Cd}$ & $\mathrm{Zn}$ \\
\hline $\mathrm{n}=2$ & delocalized & delocalized & delocalized \\
\hline $\mathrm{n}=3$ & delocalized & delocalized & delocalized \\
\hline $\mathrm{n}=4$ & 0.95 & delocalized & delocalized \\
\hline $\mathrm{n}=5$ & 0.66 & delocalized & delocalized \\
\hline $\mathrm{n}=6$ & 0.51 & delocalized & delocalized \\
\hline $\mathrm{n}=7$ & 0.45 & delocalized & delocalized \\
\hline
\end{tabular}

TABLE IV: The first ionization potential $\mathrm{I}_{P}\left(\mathrm{X}_{n}\right)$ with $\mathrm{X}=\mathrm{Hg}, \mathrm{Cd}$ or $\mathrm{Zn}$.

\begin{tabular}{|c|c|c|c|c|c|}
\hline $\mathrm{I}_{P}\left(\mathrm{X}_{n}\right)(\mathrm{eV})$ & $\mathrm{Hg}_{n}$ & $\mathrm{Cd}_{n}$ & $\mathrm{Zn}_{n}$ & $\mathrm{Hg}_{n} \exp$ in $\operatorname{Ref}[3]$ & $\mathrm{Cd}_{n} \exp$ in Ref[19] \\
\hline $\mathrm{n}=1$ & 10.43 & 9.0 & 9.39 & 10.43 & 9 \\
\hline $\mathrm{n}=2$ & 9.4 & 8.18 & 8.58 & 9.4 & 7.8 \\
\hline $\mathrm{n}=3$ & 8.9 & 7.47 & 7.84 & 8.9 & 7.1 \\
\hline $\mathrm{n}=4$ & 8.65 & 6.85 & 7.21 & 8.65 & 6.8 \\
\hline $\mathrm{n}=5$ & 8.63 & 6.64 & 6.94 & 8.6 & 6.6 \\
\hline $\mathrm{n}=6$ & 8.58 & 6.58 & 6.88 & 8.5 & 6.5 \\
\hline $\mathrm{n}=7$ & 8.5 & 6.45 & 6.72 & 8.35 & 6.3 \\
\hline
\end{tabular}


TABLE V: The vertical second ionization potential $\mathrm{I}_{P}^{I I}\left(\mathrm{X}_{n}\right)$ with $\mathrm{X}=\mathrm{Hg}, \mathrm{Cd}$ or $\mathrm{Zn}$.

\begin{tabular}{|c|c|c|c|}
\hline $\mathrm{I}_{P}^{I I}\left(\mathrm{X}_{n}\right)(\mathrm{eV})$ & $\mathrm{Hg}_{n}$ & $\mathrm{Cd}_{n}$ & $\mathrm{Zn}_{n}$ \\
\hline $\mathrm{n}=1$ & 18.75 & 16.90 & 17.96 \\
\hline $\mathrm{n}=2$ & 14.70 & 13.08 & 13.54 \\
\hline $\mathrm{n}=3$ & 12.95 & 11.93 & 12.42 \\
\hline $\mathrm{n}=4$ & 10.92 & 10.87 & 11.35 \\
\hline
\end{tabular}

TABLE VI: The atomization energy $\mathrm{D}_{E}(\mathrm{eV})$ of $\mathrm{X}_{n}^{++}$with $\mathrm{X}=\mathrm{Hg}, \mathrm{Cd}$ or $\mathrm{Zn}$.

\begin{tabular}{|c|c|c|c|}
\hline $\mathrm{D}_{E}(\mathrm{eV})$ & $\mathrm{Hg}_{n}^{++}$ & $\mathrm{Cd}_{n}^{++}$ & $\mathrm{Zn}_{n}^{++}$ \\
\hline $\mathrm{n}=2$ & 3.19 & 3.20 & 3.28 \\
\hline $\mathrm{n}=3$ & 0.81 & 1.20 & 1.29 \\
\hline $\mathrm{n}=4$ & -1.43 & -0.72 & -0.69 \\
\hline
\end{tabular}

TABLE VII: The fragmentation energy $\mathrm{E}_{Q}(\mathrm{eV})$ of $\mathrm{X}_{n}^{++}$with $\mathrm{X}=\mathrm{Hg}$, Cd or $\mathrm{Zn}$ for different fragmentation channels.

\begin{tabular}{|c|c|c|c|}
\hline $\mathrm{E}_{Q}(\mathrm{eV})$ & $\mathrm{Hg}$ & $\mathrm{Cd}$ & $\mathrm{Zn}$ \\
\hline $\mathrm{X}_{4}^{++} \rightarrow \mathrm{X}_{2}^{+}+\mathrm{X}_{2}^{+}$ & -0.70 & -1.04 & -1.14 \\
\hline $\mathrm{X}_{4}^{++} \rightarrow \mathrm{X}_{2}^{+}+\mathrm{X}^{+}+\mathrm{X}$ & 0.36 & -0.23 & -0.24 \\
\hline $\mathrm{X}_{4}^{++} \rightarrow 2 \mathrm{X}^{+}+2 \mathrm{X}$ & 2.02 & 0.57 & 0.64 \\
\hline $\mathrm{X}_{4}^{++} \rightarrow \mathrm{X}_{3}^{+}+\mathrm{X}^{+}$ & -0.26 & -1.09 & -1.11 \\
\hline
\end{tabular}

